\title{
Dynamic characteristics of serotonin and dopamine metabolism in the rainbow trout brain: a regional study using liquid chromatography with electrochemical detection
}

\author{
C. Saligaut ${ }^{1}$, T. Bailhache ${ }^{1}$, G. Salbert ${ }^{1}$, B. Breton ${ }^{2}$ and P. Jego ${ }^{1}$ \\ ${ }^{1}$ Laboratoire de Physiologie des Régulations, UA CNRS 256, Campus de Beaulieu, 35042 Rennes Cédex, \\ France; ${ }^{2}$ Laboratoire de Physiologie des Poissons (INRA), Campus de Beaulieu, 35042 Rennes Cédex, \\ France
}

Keywords: rainbow trout, dopamine, serotonin, metabolites, brain, pituitary, liquid chromatography, COMT

\begin{abstract}
Aminergic metabolism was studied in discrete brain regions of the postovulated female rainbow trout using a liquid chromatography electrochemical detection method. 3 Methoxytyramine (3MT) was the major dopaminergic catabolite, suggesting that catechol-o-methyl transferase is the main dopamine (DA) catabolic enzyme. Two populations of brain regions were found: one with a high DA content and low 3MT/DA ratio (hypothalamus and telencephalon), suggesting that these regions could present a high density of DA perikarya; the other with a high 3MT/DA ratio (pituitary, preoptic area, myelencephalon and optic tectum) suggesting that these regions could present a high density of DA axonal endings. 5 Hydroxytryptamine (5HT) content differed, but an homogeneous distribution of monoamine oxidase was found in different brain regions. High $5 \mathrm{HT}$ content was found in the hypothalamus and telencephalon; $5 \mathrm{HT}$ was however not detectable in the pituitary.
\end{abstract}

\section{Introduction}

In the past decade, high performance liquid chromatography - electrochemical detection (HPLCECD) has been used extensively in mammalian species to determine the characteristics of brain aminergic metabolism. Little is known about aminergic metabolism in teleost fishes and especially in salmonids. Histochemical fluorescent, immunocytochemical or autoradiographic methods allow cells containing amines or amine receptors to be localised in brain tissue from several fishes: eel (Popek 1983), goldfish (Kah et al. 1984a, 1986), salmon and rainbow trout (Terlou and Ekengren 1979). Pharmacological experiments in fish, focused on the relationships between brain metabolites and neurohormonal secretions of the pituitary, have delineated the important role of aminergic metabolism (Peter and Paulencu 1980; Billard et al. 1984; Chang et al. 1984a, b; De Leeuw et al. 1986; Van Der Kraak et al. 1986). However, HPLC-ECD methods have not been used extensively (Sebert et al. 1985).

The aim of our study was, using HPLC-ECD as an experimental procedure, to determine the physiological characteristics of both dopamine and serotonin metabolism in various brain areas of the rainbow trout, focusing on the determination of neurotransmitter contents, but also metabolite concentrations as a reflect of the aminergic turnover.

\section{Materials and methods}

Experiments were performed on 8 female rainbow trout (Salmo gairdneri) weighing about $2,000 \mathrm{~g}$. 


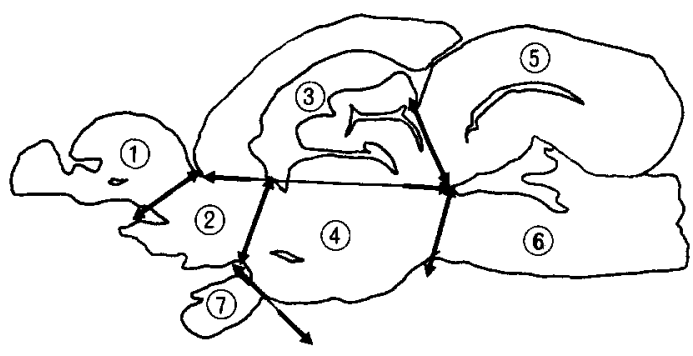

Fig. 1. Schematic diagram of a saggital section of the brain of a rainbow trout. The brains were dissected in seven regions as represented by arrows. Weights in parenthesis are expressed as $\mathrm{mg} \pm$ SEM for 8 determinations: 1 . telencephalon with olfactive tubercles $(61 \pm 4.6) ; 2$. preoptic area $(47.5 \pm 5.5)$; 3 . optic tectum $(138 \pm 8.5) ; 4$. hypothalamus $(117 \pm 9) ; 5$. cerebellum $(107$ $\pm 6.5) ; 6$. myelencephalon (126 \pm 5.3$) ; 7$. pituitary $(23 \pm 2.4)$.

They were kept in 5001 aquaria in fresh water at $13^{\circ} \mathrm{C} \pm 1$, under a natural photoperiod (Centre de Physiologie des Poissons, INRA). Water was constantly flowing in a recirculating water system and aerated by an appropriate device. In the experiments, postovulated and unanaesthetized animals (between 0 and 8 days after ovulation, between $15 / 11$ and $30 / 11 / 88$ ) were used, and samples were taken between $11.00 \mathrm{~h}$ and $15.00 \mathrm{~h}$.

The animals were killed by decapitation. The brain was rapidly removed on a cold plate $\left(+3^{\circ} \mathrm{C}\right)$ and dissected into seven regions (cerebellum, pituitary gland, preoptic area, hypothalamus, optic tectum, myelencephalon and telencephalon) as shown in Fig. 1. The tissues from the various regions of the different fishes were then pooled ( 2 tissues per tube) and stored at $-80^{\circ} \mathrm{C}$ for later HPLC assay.

After thawing, the tissues were mixed with a complex antioxidant medium (EDTA $0.05 \%$, $\mathrm{Na}_{2} \mathrm{~S}_{2} \mathrm{O}_{5} \quad 0.05 \%$, cystein $0.1 \%$ in perchloric acid $0.2 \mathrm{M} ; 1 \mathrm{ml}$ for each tissue) and homogenized with an Elvejheim Potter master and pestle. After centrifugation in Eppendorf tubes $(10,000 \times \mathrm{g},+$ $3^{\circ} \mathrm{C}, 20 \mathrm{~min}$ ), the supernatant was filtered on Millipore filters $(0.45 \mu \mathrm{m})$ and injected into the HPLC apparatus.

The effluent ( $0.1 \mathrm{M}$ phosphate buffer, $\mathrm{pH} 3.85$ containing $7.5 \%$ methanol and heptansulfonic acid (Pic B7, Waters) at a final concentration of $6 \mathrm{mM}$ ) was monitored at a flow rate of $1 \mathrm{ml} / \mathrm{min}$ in a
Merck C18 reverse phase column $(250 \times 4 \mathrm{~mm}$ inner diameter, $5 \mu \mathrm{M}$ average particle size) and amines were detected by a BAS bioanalytical system amperometric detector (range $0.5 \mathrm{nA}$ ). The signal was recorded on a Delsi integrator (Enica) and the results are given as the area under the spikes $\left(10^{-9} \mathrm{~g} / \mathrm{g}\right.$ fresh tissue $\pm \mathrm{SEM}$ for 4 separate evaluations). A solution of dopamine, serotonin and their metabolites (standard solution) was prepared in the antioxidant medium and injected at frequent intervals into the sample loop (1 standard for 5 assays; 40 min for 1 assay). Less than $10 \%$ changes in the amperometric detection were observed over one week of measurements. The recovery of catecholamines for our experimental procedure was investigated in preliminary studies using an 'overloading method': recovery rates ranged between $75 \%$ and $90 \%$ for dopamine, serotonin and their respective metabolites and for weights of tissues ranging between 40 and $150 \mathrm{mg}$.

All the chemicals were obtained from Sigma Chemical Company (USA). Statistical analysis used the Mann-Whitney non-parametric test.

\section{Results}

The tissue content of dopamine, serotonin and their metabolites are given in Fig. 2. Markedly different concentrations were found in the several brain regions: high serotonin $(5 \mathrm{HT})$ content $(>200 \mathrm{ng} / \mathrm{g}$ ) was present in the telencephalon, hypothalamus, intermediate content ( $>50 \mathrm{ng} / \mathrm{g}$ ) was observed in the preoptic area, myelencephalon and optic tectum. 5HT was at low levels in the cerebellum, and not detectable in the pituitary. A high level of dopamine (DA) (>100 ng/g) was observed in the telencephalon, hypothalamus and pituitary gland; intermediate or low levels in myelencephalon, optic tectum, preoptic area and cerebellum. 5HIAA (hydroxy-5-indolacetic acid) was the only catabolite for $5 \mathrm{HT}$. The $5 \mathrm{HIAA} / 5 \mathrm{HT}$ ratio was calculated and the results are shown in Fig. 3. The ratio had a constant value (about 0.5 ), except for the cerebellum and pituitary where 5HT levels were very low or undetectable. In all the regions studied, 3MT (3 methoxy-tyramine) appeared to be the main DA 

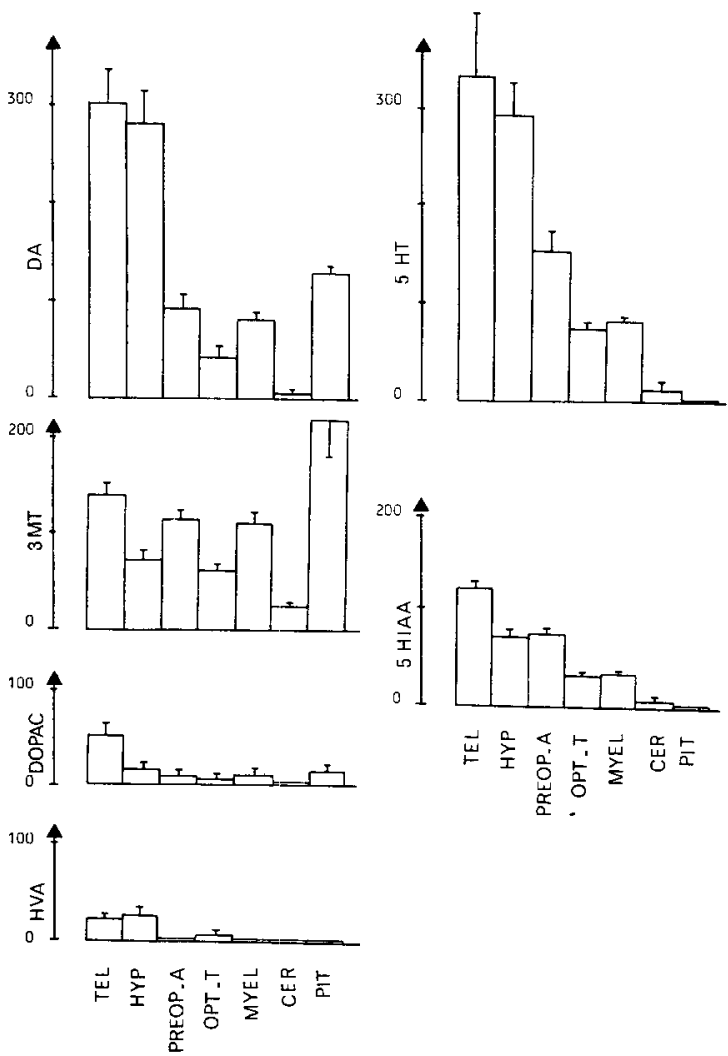

Fig. 2. Aminergic contents [dopamine (DA), serotonin (5HT)] and their respective metabolites [dihydroxy-3,4 phenylacetic acid (DOPAC); homovanillic acid (HVA); 3-methoxytyramine (3MT); hydroxy-5 indolacetic acid (5HIAA)] for seven brain regions (results are expressed in $\mathrm{ng} / \mathrm{g}$ fresh tissue \pm SEM for 4 separate evaluations). Tel: telencephalon; Hyp: hypothalamus; Preop. A: preoptic area; Opt. t: optic tectum; Myel: myelencephalon; Cer: cerebellum; Pit: pituitary.

metabolite, rather than DOPAC (dihydroxy-3,4 phenylacetic acid) or HVA (homovanillic acid) ( $p$ $<0.05$ in all the cases, Fig. 2). The 3MT/DA ratio was calculated for the 7 regions and the results are shown in Fig. 3. Two pools of DA containing tissues were observed (Fig. 3): one with intermediate DA content and a high 3MT/DA ratio (optic tectum, preoptic area, myelencephalon, pituitary), the other with a high DA content and low 3MT/DA ratio (hypothalamus and telencephalon). The DA content of the hypothalamus and telencephalon differed significantly from the DA content of the optic tectum, preoptic area, myelencephalon, pituitary $(\mathrm{p}<0.05)$, as did the $3 \mathrm{MT} / \mathrm{DA}$ ratios $(\mathrm{p}$ $<0.05$ ). Both DOPAC/DA and HVA/DA ratios
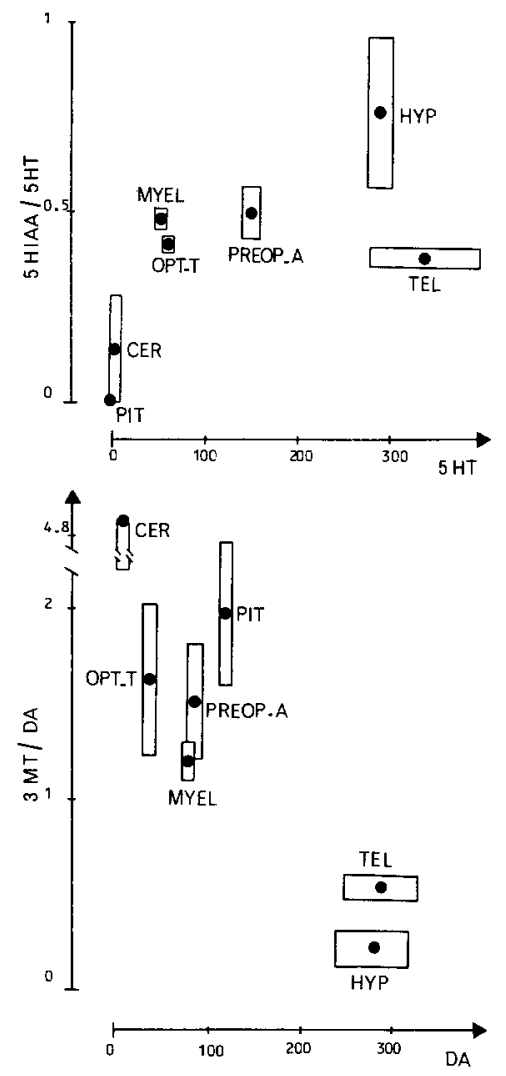

Fig. 3. 3MT/DA and 5HIAA/5HT ratios as a function of DA and $5 H T$ content in the seven brain regions. Results of ratios are the mean \pm SEM of 4 separate evaluations. No significant differences are noted between the various 5HIAA/5HT ratios. 3MT/DA ratios for the hypothalamus and telencephalon differ significantly $(p<0.05)$ from those in the other brain regions as did DA content $(p<0.05)$. For abbreviations, see the legend to Fig. 2.

were low for all the various brain regions (respective values from $0.03 \pm 0.004$ to $0.18 \pm 0.07$ and from 0 to $0.09 \pm 0.02$ for the seven regions) and did not differ significantly.

\section{Discussion}

Standard chromatograms were operated to confirm the specificity of the assay and the absence of any interference in the separation between dopaminergic compounds (DA, DOPAC, HVA, 3MT) and other aminergic compounds (norepinephrine, serotonin and their catabolites (Saligaut et al. 1986, 
1987). Norepinephrine could not be evaluated because of the interference of the solvent front.

The brain regions had markedly different aminergic profiles. The metabolism of the neurotransmitter DA is an important consideration. Evaluation of DA content alone is generally not sufficient to provide information on the metabolism of DA: for example, some physiological changes or pharmacological drugs can interfere with both DA synthesis, depending upon the activity of tyrosine hydroxylase $(\mathrm{TH})$ and DA catabolism, depending upon the monoamine oxidase (MAO) and catechol-o-methyl transferase (COMT) activities (Prioux-Guyonneau et al. 1979; Saligaut et al. 1986). Therefore, study of the amine catabolism is a good measure of the neurotransmitter turnover. Previous reports have shown that the DOPAC/DA, HVA/DA ratios are higher in rats than the 3MT/DA ratio: it is true for the whole rat brain, but also for some important brain regions such as the striatum and hypothalamus (about 0.2 for DOPAC/DA, 0.1 for HVA/DA and 0.02 for 3MT/DA) (Westerink and Wirix 1983; Saligaut et al. 1987). These data suggested that in rat brain DA is catabolized mainly by MAO.

Important changes are observed in the catabolite/DA ratios for the rainbow trout and rats: in all the trout brain regions studied, the 3MT/DA ratio is much higher than both DOPAC/DA and HVA/DA ratios. Increased 3MT content may be artefactually induced during the tissue collection and/or the freezing procedure as a consequence of a COMT activation; 3MT content should be then consistently related to DA content (i.e., the COMT substrate). This is not verified in our experiments, and our data suggest that the catabolism of DA in the trout brain is mediated mainly by the COMT enzyme.

The DOPAC and HVA content are the result of MAO activity. This enzyme is located on the external membranes of cytoplasmic mitochondria (Brown et al. 1975). COMT is however located on the synaptic cleft, more specifically in glial cells (Broch and Fonnum 1972; Kaplan et al. 1979). The $3 \mathrm{MT}$ content reflects both DA release and COMT activity, an increase in 3MT content being related to an increase of DA availability in the synaptic cleft and/or an increase in COMT activity (Kehr 1976). These properties of COMT and MAO partially explain the existence of a high DOPAC/DA ratio in rats relative to the $3 \mathrm{MT} / \mathrm{DA}$ ratio: indeed more than $80 \%$ synaptic DA is uptaken by specific 'reuptake mechanisms' in rats with a subsequent DA transfer to a presynaptic cytosolic pool and a subsequent cytosolic catabolism by MAO. We can then suggest that the high $3 \mathrm{MT}$ content in trout relative to the rat could be mediated by a decrease of DA reuptake and/or an increase in COMT activity. Such an increase in COMT activity in fish compared to the COMT activity in mammals has been recently reported for the African catfish (Clarias gariepinus) (Timmers and Lambert 1988).

These properties of MAO and COMT also support the hypothesis that both the 3MT content and the $3 \mathrm{MT} / \mathrm{DA}$ ratio should be high in those brain regions which contain axonal DA endings (i.e., brain regions with a high DA release) and low in brain regions without DA nerves or containing of DA cell bodies with a low density of DA endings. This argument gives an explanation for the discrepancy between 3MT/DA ratios in our experiment. A low 3MT/DA ratio was observed for hypothalamus and telencephalon (respectively $0.27 \pm$ 0.05 and $0.49 \pm 0.04$ ), with high DA contents (more than $200 \mathrm{ng} / \mathrm{g}$ ). This suggests that telencephalon and hypothalamus could have a high density in dopaminergic perikarya. These data agree with previous reports of the literature. Using the Falck-Hillarp fluorescence reaction, the presence of aminergic cell bodies in the nucleus recessus lateralis (NRL) and the nucleus recessus posterioris (NRP) of the hypothalamus has been observed in salmonids (Terlou et al. 1978). Catecholaminergic fibers had also been observed in the telencephalon of the goldfish (Etcheler and Saidel 1981).

A high 3MT/DA ratio was observed for the cerebellum, but this result had a minor interest, because of low content of both DA and 3MT.

A high 3MT/DA ratio, with intermediate DA content, was observed in the preoptic area, reflecting the presence of DA endings. Previous reports on salmonids already showed the aminergic innervation of the cells of the nucleus preopticus (Terlou et al. 1978). However, morphofunctional tech- 
niques in the goldfish allowed the detection of cell bodies containing catecholamines in the preoptic area (Kah et al. 1984b).

A high $3 \mathrm{MT} / \mathrm{DA}$ ratio $(1.95 \pm 0.38)$ with intermediate DA content (more than $100 \mathrm{ng} / \mathrm{g}$ ) was also found in the pituitary, suggesting that the pituitary is enriched in DA axonal endings. This supports previous reports of the literature, using histochemical methods in teleosts (Terlou et al. 1978; Terlou and Ekengren 1979; Kah et al. 1986: Wilson and Dodd 1973; Peute et al. 1987). The teleostean hypothalamopituitary system is unique among vertebrates. There is a direct innervation of the pars distalis by the neurosecretory neurons of the hypothalamus (absence of the typical mammalian hypothalamo-hypophysial portal vascular system) (Peter and Fryer 1983). Relations between hypothalamic neurons and both rostral and proximal pars distalis have been extensively studied (see review Peter and Fryer 1983), but many aspects of the hypothalamic controls of neurohormonal secretions of the pituitary are still a matter of speculation. The mechanisms for regulation of prolactin secretion in the rainbow trout were previously investigated in in vitro studies by Johnston and Wigham (1988). These mechanisms partially depend upon dopamine receptors activation. The literature concerning a dopamine-induced inhibitory effect of the gonadotropin $(\mathrm{GtH})$ release is well documented, specially for the goldfish and to a lesser extent for the other species. A direct dopamine inhibition of both spontaneous and GtH-releasing hormone induced $\mathrm{GtH}$ release was demonstrated in vitro in goldfish (Chang et al. 1984a) and in the catfish (De Leeuw et al. 1986). A temporal increase in serum GtH levels in response to domperidone was correlated to the time course of pituitary accumulation of $\left[{ }^{3} \mathrm{H}\right]$ domperidone (Omeljaniuk et al. 1987). These authors indicated that dopamine inhibits GtH secretion in the goldfish via the stimulation of pituitary dopamine- $\mathrm{D}_{2}$-receptors. Pimozide in salmon caused a marked potentiation of the $\mathrm{GtH}$ release response to a luteinizing hormonereleasing hormone analogue (LHRHA), whereas pimozide alone was ineffective (Van Der Kraak et al. 1986): these data supported the concept that dopamine participates in the regulation of $\mathrm{GtH}$ secretion in teleosts, but a direct action on pituitary DA receptors was not proven.

Little is known about serotonergic metabolism in fishes. The catabolism of $5 \mathrm{HT}$ is mediated by MAO alone, with a subsequent synthesis of 5HIAA (Blaschko and Levine 1966). In trout, the different brain regions contain different amounts of $5 \mathrm{HT}$ and 5HIAA. However, the 5HIAA/5HT ratio has a constant value in all brain regions that contain 5HT. These data suggest an homogeneous distribution of MAO in 5HT nerves. High 5HT contents are observed in the hypothalamus and telencephalon. 5HT immunoreactive perikarya have already been observed in the posterior hypothalamus of the goldfish, providing a morphological substrate for involvement of 5HT in the regulation of the pituitary gland (Kah and Chambolle 1983). 5HT fibers, but not $5 \mathrm{HT}$ cell bodies were observed also in the telencephalon of the goldfish (Kah and Chambolle 1983). However, SHT was not detectable in the pituitary gland. This observation may be important for future physiological or pharmacological studies in endocrinology.

Neurohormonal secretions of the pituitary have been shown to depend upon serotonergic pathways in other teleostean species than salmonids (Groves and Batten 1986; Kah and Chambolle 1983; Somoza et al. 1988). Olcese et al. (1981) showed, in the rainbow trout, that a serotonergic mechanism could be involved in the regulation of pituitary cyclic AMP levels, but there was no evidence of a direct action (e.g., presence of 5HT endings). Our data support an indirect mechanism, perhaps via changes of the hypothalamic metabolism of others neurotransmitters.

In conclusion, HPLC offers an alternative method for examination of changes in aminergic metabolism and may support experimental studies in binding, immuno- or fluocytochemical methods. The use of the HPLC method has shown relationships between metabolism of DA neurons (evidence for tissues with DA cell bodies and/or DA axonal endings) and the mapping of brain catecholamine pathways.

Further experiments are, however, required to delineate the mechanism of action for amines in the fish brain, focusing on the following: 
1. The main role of COMT catabolic activity in the brain. Our data agree with recent reports of Timmers and Lambert (1988) who demonstrated that in the African catfish (Clarias gariepinus) COMT interfers with both aminergic and steroid metabolisms. Their experiments also demonstrated that the $\mathrm{Km}$ values obtained for the COMT enzyme are considerably lower than those mentioned in the literature for this enzyme present in mammalian tissues (i.e., a much higher affinity of the catechol substrates for the COMT was evident in the African catfish brain).

2 . The relationships between aminergic metabolism and neurohormonal secretions during various physiological events, such as reproduction cycle and growth. The main catecholaminergic innervation of the hypothalamus, preoptic area and pituitary demonstrated here argues for such a relationship.

\section{Acknowledgements}

The authors thank M.B. Naudin (U.A. CNRS 1170) for his technical assistance. The investigators were supported by a grant of Ministère de l'Education Nationale, Direction de la Recherche.

\section{References cited}

Billard, R., Reinaud, P., Hollenbecq, M.G. and Breton, B. 1984. Advancement and synchronisation of spawning in Salmo gairdneri and $S$. trutta following administration of LRH-a combined or not with pimozide. Aquaculture 43: $59-66$.

Blaschko, H. and Levine, W.G. 1966. Metabolism of indolealkylamines. In Handbook of Experimental Pharmacology. Vol. 19, pp. 212-244. Edited by O. Eichler and A. Farah. Springer Verlag, Berlin.

Broch, O.J. and Fonnum, F. 1972. The regional and subcellular distribution of catechol-O-methyl transferase in the rat brain. J. Neurochem. 19: 2049-2055.

Brown, R.M., Kehr, W. and Carlsson, A. 1975. Functional and biochemical aspects of catecholamine metabolism in brain under hypoxia. Brain Res. 85: 491-509.

Chang, J.P., MacKenzie, D.S., Gould, D.R. and Peter, R.E. 1984a. Effects of dopamine and norepinephrine on the in vitro spontaneous and gonadotropin-releasing hormoneinduced gonadotropin release by dispersed cells or fragments of the goldfish pituitary. Life Sci. 35: 2027-2033.

Chang, J.P., Peter, R.E., Nahorniak, C.S. and Sokolowska, M. 1984b. Effects of catecholaminergic agonists and antagonists on serum gonadotropin concentrations and ovulation in goldfish: evidence for specificity of dopamine inhibition of gonadotropin secretion. Gen. Comp. Endocrinol. 55: 351360.

De Leeuw, R., Goos, H.J.Th. and Van Oordt, P.J.W.J. 1986. The dopaminergic inhibition of the gonadotropin-releasing hormone-induced gonadotropin release: an in vitro study with fragments and cell suspensions from pituitaries of the African catfish, Clarias gariepinus (Burchell). Gen. Comp. Endocrinol. 63: 171-177.

Etcheler, S.M. and Saidel, W.M. 1981. Forebrain connections in the goldfish support telencephalic homologies with land vertebrates. Science 212: 638-685.

Groves, D.J. and Batten, T.F.C. 1986. Direct control of the gonadotroph in a teleost, Poecilia latipinna. II. Neurohormones and neurotransmitters. Gen. Comp. Endocrinol. 62: 31s-326.

Johnston, L.R. and Wigham, T. 1988. The intracellular regulation of prolactin cell function in the rainbow trout, Salmo gairdneri. Gen. Comp. Endocrinol. 71: 284-291.

Kah, O. and Chambolle, P. 1983. Serotonin in the brain of the goldfish Carassius auratus: An immunohistochemical study. Cell. Tiss. Res. 234: 319-333.

Kah, O., Dubourg, P., Chambolle, P. and Calas, A. 1984a. Ultrastructural identification of catecholaminergic fibers in the goldfish pituitary. Cell. Tiss. Res. 238: 621-626.

Kah, O., Chambolle, P., Thibault, J. and Geffard, M. 1984b. Existence of dopaminergic neurons in the preoptic region of the goldfish. Neurosci. Lett. 48: 293-298.

Kah, O., Dubourg, P., Onteniente, B., Geffard, M. and Calas, A. 1986. The dopaminergic innervation of the goldfish pituitary; an immunocytochemical study at the electronmicroscope level using antibodies against dopamine. Cell Tiss. Res. 244: 577-582.

Kaplan, G.P., Hartman, B.K. and Creveling, C.R. 1979. Immunohistochemical demonstration of catechol-O-methyltransferase in mammalian brain. Brain Res. 167: 241-250.

Kehr, W. 1976. 3-methoxytyramine as an indicator of impulseinduced dopamine release in rat brain in vivo. NaunynSchmiedeberg's Arch. Pharmacol. 293: 209-215.

Olcese, J., Figueroa, H., Hamm, T.R., Yurgens, P., Kiebzak, G., Meyer, R. and De Vlaming, V. 1981. Effects of parachlorophenylalanine, a brain serotonin depletor, on pituitary cyclic AMP levels in the rainbow trout, Salmo gairdneri. Gen. Comp. Endocrinol. 43: 462-466.

Omeljaniuk, R.J., Shik, S.H. and Peter, R.E. 1987. In vivo evaluation of dopamine receptor-mediated inhibition of gonadotropin secretion from the pituitary gland of the goldfish, Carassius auratus. J. Endocrinol. 114: 449-458.

Peter, R.E. and Paulencu, C.R. 1980. Involvement of the preoptic region in gonadotropin release-inhibition in goldfish, Carassius auratus. Neuroendocrinology 31: 133-141.

Peter, R.E. and Fryer, J.N. 1983. Endocrine functions of the 
hypothalamus of Actinopterygians. In Fish Neurobiology; Higher Brain Areas and Functions. Vol. 2, pp. 165-201. Edited by R.E. Davis and R.G. Northcutt. University of Michigan Press, Ann Arbor.

Peute, J., Schild, R.G., Schild, V.A., Buijs, R.M., Van Asselt, L.A.C. and Van Oordt, J.G.W.J. 1987. Immunocytochemical evidence for peptidergic ( $\mathrm{GnRH}$ ) and dopaminergic innervation of the gonadotropic cells in the pituitary of the African catfish, Clarias gariepinus. Gen. Comp. Endocrinol. 67: 303-310.

Popek, W. 1983. Seasonal variations in circadian rhythm of hypothalamic catecholamine content in the eel (Anguilla anguilla L.). Comp. Biochem. Physiol. 75: 193-198.

Prioux-Guyonneau, M., Cretet, E., Jacquot, C., Rapin, J.R. and Cohen, Y. 1979. The effects of various simulated altitudes on the turnover of norepinephrine and dopamine in the central nervous system of rats. Pflügers Arch. 380: 127-132.

Saligaut, C., Chretien, P., Daoust, M., Moore, N. and Boismare, F. 1986. Dynamic characteristics of dopamine, norepinephrine and serotonin metabolism in axonal endings of the rat hypothalamus and striatum during hypoxia: a study using HPLC with electrochemical detection. Meth. Find. Exp. Clin. Pharmacol. 8: 343-349.

Saligaut, C., Daoust, M., Moore, N. and Boismare, F. 1987. Effects of hypoxia and cytidine (5') diphosphocholine on the concentrations of dopamine, norepinephrine and metabolites in rat hypothalamus and striatum. Arch. Int. Pharmacodyn. Ther. 285: 25-33.
Sebert, P., Barthelemy, L. and Caroff, J. 1985. Serotonin levels in fish brain: effects of hydrostatic pressure and water temperature. Experientia 41: 2049-2055.

Somoza, G.M., Yu, K.L. and Peter, R.E. 1988. Serotonin stimulates gonadotropin release in female and male goldfish Carassius auratus L. Gen. Comp. Endocrinol. 72: 373-382.

Terlou, M., Ekengren, B. and Hiemstra, K. 1978. Localization of monoamines in the forebrain of two salmonid species, with special reference to the hypothalamohypophysial system. Cell Tiss. Res. 190: 417-438.

Terlou, M. and Ekengren, B. 1979. Nucleus praeopticus and nucleus lateralis tuberis of Salmo salar and Salmo gairdneri structure and relationship to the hypophysis. Cell Tiss. Res. 197: 1-21.

Timmers, R.J.M. and Lambert, J.G.D., 1988. Kinetic studies of catechol-o-methyltransferase from the brain of the African catfish, Clarias gariepinus. Comp. Biochem. Physiol. 91C: 399-402.

Van Der Kraak, G., Donaldson, E.M. and Chang, J.P. 1986. Dopamine involvement in the regulation of gonadotropin secretion in coho salmon. Can. J. Zool. 64: 1245-1248.

Westerink, B.H.C. and Wirix, E. 1983. On the significance of tyrosine for the synthesis and catabolism of dopamine in rat brain: Evaluation by liquid chromatography with electrochemical detection. J. Neurochem. 40: 758-764.

Wilson, J.F. and Dodd, J.M. 1973. Distribution of monoamines in the diencephalon and pituitary of the dogfish, Scyliorhinus canicula L. Z. Zellforsch. Mikros. Anat. 137: 451-469. 